\title{
Masculine Ideology and Gender Role Conflict among Pastor's Husband
}

\author{
Karina Meriem Beru Brahmana \\ Lecturer at Faculty of Psychology \\ Universitas HKBP Nommensen Medan \\ ina_brahmana@yahoo.com \\ Suryanto \\ Faculty of Psychology \\ Universitas Airlangga Surabaya \\ suryanto@psikologi.unair.ac.id \\ Bagong Suyanto \\ Faculty of Sociology \\ Universitas Airlangga Surabaya \\ bagong_fisip@yahoo.com
}

\begin{abstract}
This study aims to measure the correlation between masculine ideology and gender role conflict among the pastor's husband. This study included 40 GBKP pastors' husbands using two measuring scales, namely the male role norm scale compiled by Thompson \&Pleck (1986) and the gender role conflict scale compiled by $\mathrm{O}^{\prime} \mathrm{Neil}$ et al. (1986). Pearson product-moment correlation coefficient statistics revealed a positive relationship between masculine ideology and gender role conflict, $r=0.484$ at $p<.05$. The findings were discussed, and suggestions made.
\end{abstract}

Keywords: Masculine ideology, gender role conflict, pastor

Received 29 August2019/Accepted 29November 2019 @JEHCP All rights reserved

\section{Introduction}

Being a man is not as easy as it seems. A man should fulfill some demands in order to be able to show his identity based on the roles applied in his society. Those demands generally have been defined by the society or the culture in which he grew up, and they will have impacts or consequences for each individual (O’Neil, 2008, 2015).

As an individual that was born a man, the demand for becoming a person that is strong, dependable, tough, and able to outperform women has to be fulfilled (Farrel, 1975). Those 
demands are also known as gender roles. According to Debiaggi (2002), gender role is personal characteristics, responsibilities, and behavior deemed appropriate for women and men in certain cultures.

Karo tribe in North Sumatera embraces the patriarchal values where men hold the highest power in society (Bangun I98I; Tarigan, 2009). As a tribe that embraces the patriarchal culture, the Karo people generally also recognize differences and distinguish humans based on sex, not only in accordance with physical realities but also their influence in social life(Bangun, 198I). In Karo culture, men who are performing a task that is considered less appropriate to one's gender can reduce or decrease one's dignity (Bangun, 198I). For example, a man who is taking care of children in the middle of a traditional ceremony can reduce the dignity of men. Men who often do such work, or other jobs that are supposed to be women's work, are called pa diberuor men who are ordered by their wives or women (Bangun, 1981). When a Karo man is forced or voluntarily to carry out a task or role that is contrary to the demands of his culture and environment, it will generally lead to inner conflicts that cause feelings of discomfort and have a greater impact such as the emergence of feelings of shame, anger or fighting with other people.

In Karo culture, sex generally determines one's position in social layers. Karo people believe that men's position is higher than women's. Being a man is the reason that places one in a higher position within the society. It can be seen on how Karo's tradition puts a man or a husband as a person who can make a decision (Bangun, 198I). Moreover, the higher position of men or husbands can also be seen on how the women or wives pay their respect. For example, in a traditional ceremony or family gathering, men sit at the front seat and are the first one that is being served (e.g., at mealtime) before women (Bangun, 198I).

Men's position in social layers explained above applies to all men in the Karo tribe, and the husband of a pastor serving at KaroBatakProtestanChurch(GBKP) is no exception. As a man of the Karo tribe, a husband is generally expected to be a leader and has a significant influence on 
his family. Moreover, the patrilineal cultural system demands that men can outperform women in various aspects(Williams \& Best, in Courtenay, 2000).

However, the reality is different when he (the men) married to a pastor (woman) serving at GBKP. As a member of family serving God, the pastor's husband also has a big responsibility in supporting his wife. Naras, a term used for the pastor's husband in the service where his wife serves, is expected to show his concerns and attention to the congregations, church environment and the surrounding community. In addition, the husband is expected to support his wife's service in accordance with his gift or talent, equip themselves to support his wife's service in the spiritual field and daily life, reminding his wife as a servant of God to give best services to the congregation, does not involve or organize his wife's service work and does not become a barrier in his wife's service (PPWG GBKP, 20I4). Therefore, it can be assumed that being the pastor's husband is not easy.

The moral responsibility given to the pastor's husband is due to the immense pastor's service (as a Shepherd, a Teacher, and a Leader) and their always mobile service duties (PPWG GBKP, 20l4). The duties, where the congregation needs more attention, tend to make the husband feel ignored. In addition, due to many services a wife has to do in her daily life, many women pastors sometimes cannot actively perform their role as a housewife who have to cook, do housework, parenting and other domestic duties. Therefore, husbands (naras) are expected to perform the role or task, either voluntarily or not.

In addition to performing the roles that are contrary to their gender roles, naras or husbands are also confronted with situations where they have to quit their jobs and join their wives' service. This is because the pastors are constantly mobile and must be ready when being transferred by the central office. These conditions generally tend to make it difficult for the husband to have a permanent job, so the husband eventually decides to participate in his wife's service without having other jobs, or they choose to be an entrepreneur (open workshop, farming, etc.).In this case, the husband is expected to leave his ego as a man to help his wife's 
service by taking care of their children while his wife does her task or preach, helping with housework (such as cooking, doing laundry, ironing clothes, etc.), and by driving or picking up his wife while she works.

These conditions generally lead to problems for the husband. Moreover, men in the Karo tribe have a higher position and play a significant role. The condition of a husband that cannot optimally actualize and develop himself in his work of interest leads him to an unpleasant situation and dilemma.Moreover, the roles are not in accordance with gender role demands expected by the environment and culture (O'Neil, 20I5).

A common perception of nonconformity occurs when a person feels the performed task is not in accordance with his or her interests, skills and values. Such conditions are called role conflict by some experts. According to Baron (in Chusmir\&Koberg, 1986), role conflict is the result of individual experiences where the expectations of others about their behavior are not consistent with the expectations of the individual itself. The inconsistency occurs due to differences in the socialization process, and the conflict originates or stems from intrapersonal, intra-role or inter-role mismatches. Naylor et al. (1980) argued that role conflict can also occur when individuals have more than one source for role expectations, and they cannot satisfy all these expectations, for instance when an individual cannot fulfill the expectation of the role he must perform from home as a father or husband and from society as a man.

Role conflicts occur because a man or woman cannot carry out the expected role of the community or norms / rules that apply in his environment are generally referred to as gender role conflict or gender role conflict (O'Neil, 20I6). The concept of gender role conflict in men began in the late 1970s, where the focus of research on gender was more on women and very little on men.The movement of women in the 1970s or known as the emancipation of women became the basis of increasing concern for women (O'Neil, 198Ib) so that men seemed to be neglected. O'Neil (198Ib) said that in the late 1970s until the early 1980s is a time when men began to realize that they were also the victims of sexist gender role socialization in their lives. 
O'Neil et al. (2008) found four patterns to measure male gender role conflicts. Restricted Emotion (RE) describes men's fear and limitations to express emotion, discover and use words as forms of expressing feelings. The second is Restrictive Affectionate Behavior Between Men (RABBM), which is defined as limitations to express feelings and thoughts to others as well as physical contact difficulties with men. The third pattern is Success/Power/Competition (SPC), a reflection of personal attitude towards roles in relation to competition and power to achieve success. The fourth pattern, Conflict Between Work and Family Relations (CBWFR), describes men's difficulties in balancing working/school commitment in relation to family and friends. CBWFR often reduces spare time or relaxation that subsequently poses health problems, stress and work compulsion.

The negative impact arise as a result of sexiest and rigid gender role socialization, so that when a man act different from the gender role expected of him, they will have uncomfortable feelings that lead to negative things (O'Neil, 20I5). This condition also occurs in the pastor's husband, where his ability to be a breadwinner and his responsibility to help household chores is contradictive with his ideology. In addition, differences between reality and belief about the current role also causes conflict in the husbands, where Pleck and O'Neil called this concept as masculine ideology.

O'Neil (2008) said that the emergence of gender role conflict is generally related to gender role socialization since childhood and masculine ideology. According to Pleck (1995), masculine ideology is a belief about how crucial it is for a man to follow the traditional gender role, which has been long set and supports this belief in internalizing the system of masculinity for men. Masculine ideology is the main way for men to live according to values that now have been considered sexist and patriarchal, and bring more negative impact for their interpersonal relationship or interaction with other people(O’Neil, 2008; Pelck, 1995). 
Researches related to the theory of gender role conflict in men (which was first built by James O'Neil in the late 1970s, until now still being carried out in various countries in the world, but in Indonesia research on this subject is still limited. Based on the results of a presentation conducted by $\mathrm{O}^{\prime} \mathrm{Neil}(20 \mathrm{II})$ on the activities of The International Conference "Future Perspectives on Intervention, Policy, and Research on Men and Masculinity" at Laval University, Quebec City, Canada, it is known that research on gender role conflict conducted in Indonesia is still minimal, that only amounts to 2 studies and I research in the form of a thesis (not published).

Besides the dominance of the tribes in Indonesia who adhere to the patrilineal family system and consider the massive impact on men, this research is considered essential and needs to be done, especially on the pastor's husband. The importance of the husband's role in the pastor's service to the congregation and also the church as an organization is also another important reason for conducting this research. The benefits of doing this research are not just giving a description of the conditions experienced by the pastor's husband related to the gender role conflict he experienced, but also about his masculine ideology, besides that this research is also beneficial for GBKP (KaroBatakProtestant Church) as an organization to be able to compile and develop programs and follow-up plans for the Pastor's husbands, considering that the number of women becoming pastors in GBKP is increasing every year.

Research on gender role conflict in the pastor's husband in the KaroBatak Protestant Church is also important to do in order to accomplish the gender role conflict theory developed by O'Neil, especially relating to situational contexts. From the beginning, gender role conflict research in men generally was not directly aimed at multi-cultural and religious issues as a factor of men's problems related to the socialization of their gender roles (O'Neil, 20I6). This is encouraging Addis, Mandfield, \&Syzdek (2010) and Jones \&Heesacker (2012) to declare and provide criticism so that gender role conflict can be examined more broadly in a macro contextual, micro contextual and situational context. Research into gender role conflict in the 
context of the church (contextual), in this case, is in the KaroBatak Protestant Church and is expected to complement the lackof the theory proposed by O'Neil.

In addition, in its development, the most recent research on gender role conflict provides suggestions that research related to this topic can also be linked to topics related to personal, social, and institutional discrimination and social injustice against men (O'Neil, 20I5). Critics also argue that gender role conflict in men has generally not been contextualized, thus assuming that the situation and real-life of men have been ignored in gender role conflict theory and research (Addis,Mandfield, \&Syzdek, 20I0; Jones \&Heesacker, 2012; O'Neil, 2008). Research on gender role conflict in the pastor's husband can provide meaningful input for the development of gender role conflict theory in relation to masculine ideology.

Research question

Does masculine ideology have a relationship towards gender-role conflict of GBKP pastors' husbands?

\section{Method}

Research design

Explanatory research was conducted to highlight a correlation among research variables and to test the hypothesis (Singarimbum\& Effendi, 2006). The writer proposed a hypothesis that there was a significant correlation between masculine ideology and gender role conflict in pastor's husbands serving at GBKP. The independent variable in this study was a masculine ideology, while the dependent variable was gender role conflict.

\section{Research subject}

Before the study was conducted, the researcher first sent a permit request to the leader of the Karo Batak Protestant Church (GBKP), which was then approved for data collection. In 
addition, at the time of data collection, researchers also asked about the willingness of research subjects and provided a sheet of willingness as a research respondent (inform consent). After the willingness sheet is approved, the research subjects can fill out the research questionnaire.

This study employed 40 pastor's husbands serving at GBKP, with ages ranged from 25-60 years old. The subjects should meet the following criteria: having been married for at least one year, having at least one child, a native of Karo tribe, and a member of GBKP since before marriage.

\section{Measurements}

This study used two variables, namely gender role conflict and masculine ideology.

The data were collected using the following scales:

\section{Gender Role Conflict}

In order to measure gender role conflict encountered by the pastor's husband, we used Gender Role Conflict Scaledeveloped by O'Neil et al. (1986) with 37 items, where the response is represented by a 6 point Likert scale ( $I=$ strongly disagree; $6=$ strongly agree). This scale consists of 4 related indicators that can measure conditions of gender role conflict experienced by men, namely Restricted Emotionality (RE), Restrictive Affectionate Behavior Between Men (RABBM), Success / Power / Competition (SPC) and Conflict between Work and Family Relations (CBWFR). Based on the trial results measuring the gender role conflict using Lisrel 8.50, it is known that of the 37 items of gender role conflict, 23 items were declared valid, and 14 items were declared invalid with the reliability of 0.723 . The following are examples of items on this scale: "Moving up the career ladder is important for me", I have difficulty telling others I care about them" and "Expressing feelings makes me feel open to attack by other people". 
Masculine Ideology

Masculine ideology was measured using the Male Role Norms Scale (MRNS) proposed by Thompson \& Pleck (1986). This scale was developed from the short form of the Brannon Masculinity Scale and consisted of 26 items. This scale consists of 3 (three) indicators, namely Status Norms, Anti-Femininity, and Toughness. The response is represented by the 7-point Likert Scale $(I=$ strongly disagree; $7=$ strongly agree $)$. Based on the results of trials of masculine ideology using Lisrel 8.50, it is known that from 26 items of masculine ideology, 17 items were declared valid, and nine items were declared invalid, with reliability of 0.733 . The following are examples of items on this scale: "The best way for a man to gain respect from others is by having a job and working hard on it", "It is embarrassing for a man to have a job that is usually performed by women" and "A man should never give up in facing problems".

\section{Data analysis}

The data were analyzed using Pearson's product-moment correlation. This correlation technique is used to find out the correlation and to prove a hypothesis of correlation between two variables. This product-moment testing was conducted using SPSSversion 24.

\section{Results}

The subjects were pastor's husband serving at GBKP that have been married for at least one year and have one child. These limitations were built upon a statement by Olson and DeFrain (2003), in which they argued that being a parent is not an easy thing. Parents have many responsibilities and roles; they even perform roles that are not in accordance with their gender roles. The results of descriptive analysis on gender role conflict scale showed that II subjects or about $27.5 \%$ of the total sample had low level of gender role conflict, while 20 subjects or $50 \%$ of the total sample were classified as having medium role conflict, and those classified as having high gender role conflicts were 9 subjects or about $22.5 \%$. On the other hand, the results of masculine ideology scale indicated 4 subjects or about $10 \%$ of the total sample had a 
low level of masculine ideology, 23 subjects or about $57 \%$ had a medium level of masculine ideology, while 13 subjects or about $33 \%$ had a high level of masculine ideology. See table I below.

Table I

Subjects' characteristics

\begin{tabular}{lccc}
\hline & Classified & Frequency & Valid Percent \\
\hline Gender Role Conflict & Low & 11 & $27.5 \%$ \\
& Medium & 20 & $50 \%$ \\
\multirow{3}{*}{ Masculine Ideology } & High & 9 & $22.5 \%$ \\
& Low & 4 & $10 \%$ \\
& Medium & 23 & $57 \%$ \\
& High & 13 & $33 \%$ \\
\hline
\end{tabular}

The Pearson'sproduct-moment correlation acquired a significant correlation between masculine ideology and gender role conflict $(r=0.484, p=0.002, p<0.05)$. This finding also indicated a positive direction of the two variables. The higher the masculine ideology had by the pastor's husbands, the higher their tendency to encounter gender role conflict. See table 2 below.

Table 2

Correlation analysis result

\begin{tabular}{|c|c|c|c|}
\hline & & GRC & MASIDEO \\
\hline \multirow[t]{3}{*}{$\overline{G R C}$} & Pearson Correlation & 1 & $.484^{* *}$ \\
\hline & Sig. (2-tailed) & & .002 \\
\hline & $\mathrm{N}$ & 40 & 40 \\
\hline \multirow[t]{3}{*}{ MASIDEO } & Pearson Correlation & $.484^{* *}$ & I \\
\hline & Sig. (2-tailed) & .002 & \\
\hline & $\mathrm{N}$ & 40 & 40 \\
\hline
\end{tabular}




\section{Discussion}

The results showed that the research hypothesis stating the correlation between masculine ideology and gender role conflict in the pastor's husbands serving at GBKP is acceptable. Therefore, there is a significant correlation between masculine ideology and gender role conflict in the pastor's husband serving at GBKP. This finding suggested that the higher the masculine ideology had by the pastor's husbands, the higher their tendency to encounter gender role conflict, and vice versa.

Wiersman and Willis (Chusmir \& Koberg, 1986) stated that gender role conflict or sex role conflict is a serious issue, and its prevalence is increasing in men. This increase brings concern, given the fact that some studies reported that male gender roles brought serious consequences related to the self (intrapersonal) or others (interpersonal)(O'Neil, 2008; Pleck, 1995).

The interview resultsshowed that the emergence of gender role conflict inpastor's husbandswas caused by the differences or conflicts between the current role and the one they have been taught since childhood. His incapability to be the leader of the family and domestic chores becoming his responsibility are the opposite of what he believes of how a man should be since he is a child. Also, what society believes about the role of a man cannot be fulfilled and practiced in his daily life, and this triggers conflict within himself. Pleck and O'Neill called this phenomenon of masculine ideology.

Pleck (1995) stated masculine ideology is a belief about how crucial it is for a man to follow the traditional gender role, which has been long set and supports this belief in internalizing the system of masculinity for men. O'Neil also stated that masculine ideology is another factor that brings up conflict and tension of gender roles in a man's inner self. Masculine ideology portrayed how a man is stereotyped with masculinity; it is a belief that men must partake in the standard set by his community. Masculine ideology emerges from gender roles, which often limits and brings negative consequences for men and their interpersonal relationships (O'Neil, 2008; Pleck, 1995). 
According to O'Neil (2008), the emersion of gender role conflict is related closely with gender role socialization since childhood and masculine ideology that men have. Pleck (1995) stated masculine ideology is a belief about how crucial it is for a male to follow the traditional gender role, which has been long set and supports this belief in internalizing the system of masculinity for males. Masculine ideology is a main tool for men to live according to values that now have been considered sexist and patriarchal and bring a more negative impact on their interpersonal relationship or interaction with other people. O'Neil (Beaglaoichet al., 20I3) stated that there are several situational contexts where gender role conflict can occur in men; one of the cases is the digression or violation of gender role norms from his masculine ideology.

The interaction and correlation that a man has with others can be interfered and limited if he finds that the ideology he lives in is different with the reality in life. It is related tightly with the phenomenon happened to the pastor's husbands; the masculinity has been internalized since they were children, but the practice of masculinity is not congruent when they have to face adulthood later in life. His incapability to be the leader of the family, and domestic chores becoming his responsibility are the opposite of what he believes of how man should be since he is a child.

The statement is supported by Baron's (2009) study that discovered that masculine ideology is related with the pressure of male gender role. In his study, he found that a man's identity or how he defines himself depends on his friend, family and community's view of him. He will be seen as having or valuing high of masculine ideology if there is a denial or a concealment of his true self and what he truly wants to become.

The results of the descriptive analysis showed that $50 \%$ of the sample had a medium level of gender role conflict, and $22.5 \%$ of the sample had a high level of gender role conflict. This matter certainly needs to be concerned about, given that the increase of those suffering from gender role conflicts will be significant if what happened to the pastor's husbands in GBKP is not given its much-needed act. 


\section{Conclusion}

This study found a significant positive relationship between masculine ideology and gender role conflict in the pastor's husbands serving at GBKP. The higher the masculine ideology had by the husbands, the higher the gender role conflict ensues. It is vice versa; the lower masculine ideology had by the husbands, the lower the gender role conflict likely to happen.

\section{Suggestion and Research Limitation}

This research is a correlational study that shows the relationship between gender role conflict and masculine ideology. This study shows the need for additional variables to be studied in order to better explain about the gender role conflict experienced by the pastor's husband in GBKP. This is consistent with the results of a summary conducted by O'Neil (2008) on the criticisms given related to gender role conflict research previously, who tend to use more correlational studies, so the complex research by including independent, dependent, and intervening (moderator and mediator) is needed.

A study about male gender role conflict in Indonesia is still limited and scarce. The writer chose this topic to be discussed, in hope for there will be many more who are interested in discovering more about male gender role conflict. This is also to raise awareness since most of Indonesian tribes believe in patrilineal relationship, so a high demand and pressure is put on man's shoulder naturally. The research is also needed, given that there are many cases of male gender role conflict in Indonesia that brings negative impact within themselves as individuals, whether it is personal or interpersonally, when gender role conflicts occur.

This study of gender role conflicts happened to the pastor's husband serving at GBKP still has several limitations. Therefore future research about the same topic should emphasize these points. The first is the sample observed. The sample taken for this research is not varied: the pastor's husband serving at GBKP only. It is highly suggested to increase the variation of churches to be taken a sample from, given that it is not only GBKP, which is the potential to 
discover the gender role conflict phenomenon. Second, the volunteers willing to be taken as a sample are 40 subjects. It will be best for future research to involve more subjects since it would broaden the view and gain more insight into the gender role conflict phenomenon.

\section{Acknowledgment}

The study was supported by a research grant from Direktorat Jenderal Penguatan Riset dan Pengembangan Kementerian Riset, Teknologi, dan Pendidikan Tinggi Republic of Indonesia, based on research contract number: 0I7/KI.I/LT.I/20I8.

\section{References}

Addis, M. E., Mansfield, A. K., \&Syzdek, M. R. (2010). Is "masculinity" a problem? Framing the effects of gendered social learning in men. Psychology of Men \& Masculinity, I I (2), 77-90. DOI: I0.1037/a0018602

Bangun, P. (198I). Pelapisan sosial di Kabanjahe. Disertasi tidak diterbitkan. Ilmu Antropologi Sosial Universitas Indonesia: Jakarta.

Barron, J.M. (2009). Masculinity ideology, gender role strain, and identity styles in male college students. Unpublished Dissertation.The University of South Dakota.

Beaglaoich, C. Ó., Sarma, K. M \& Morrison, T. G. (20I3).New directions in gender role conflict research. In Gelfer, J (Ed), Masculinities in aglobal era. New York: Springer Science+Business Media

Chusmir, L. H \& Koberg, C. S. (1986). Development and validation of the sex-role conflict scale.The Journal of Applied Behavioral Science, 22(4) 397-409.

Courtenay, W. H. (2000). Constructions of masculinity and their influence on men's well-being: a theory of gender and health. Social Science \& Medicine,50, I385-I40 I.

DeBiaggi, S. D. D. (2002). Changing gender roles: Recent immigration and american society. New York: LFB Scholarly Publishing LLC

Farrel, W. (1975). The liberated man. New York: Random House.

Jones, K. D., \& Heesacker, M. (20I2). Addressing the situation: Some evidence for the significance of microcontexts with the gender role conflict construct. Psychology of Men \& Masculinity, I3(3), 294-307. 
Naylor, J. C., Pritchard, R. D., \& Ilgen, D. R. (1980). A theory of behavior in organizations. New York: Academic Press

Olson, D. H \& DeFrain, J. (2003). Marriages and families: Intimacy, diversity and strength(4 ${ }^{\text {th }}$ Eds). New York: McGraw Hill

O'Neil, J. M. (198Ib). Patterns of gender role conflict and strain: Sexism and fear of femininity in men's lives. Personnel \& Guidance Journal, 60, 203-210.

O'Neil, J. M. (2008). Summarizing 25 years of research on men's gender role conflict using the gender role conflict scale: New research paradigms and clinical implications. The Counseling Psychologist, 36, 358-445. DOI: 10.1 I77/001 I000008317057.

O'Neil, J. M. (20I I, March). 25 years of the gender role conflict research: A thematic and empirical summary. Paper Presented at the International Conference "Future Perspectives on Intervention, Policy, and Research on Men and Masculinity," Canada.

O’Neil, J. M. (20I5). Men's Gender role conflict: Psychological cost, consequences, and an agenda for change. Washington, DC: American Psychological Association.

O'Neil, J. M, Helms, B., Gable, R., David, L., \& Wrightsman, L. (1986). Gender role conflict scale (GRCS): College men's fears of femininity. Sex Roles, 14, 335-350.

O'Neil, J.M \& Denke, R. (2016). An empirical review of gender role conflict research: New conceptual models and research paradigms. In Y.J. Wong \& S.R. Wester (Eds), APA Handbook of Men and Masculinities. The American Psychological Association.

Pleck, J. H. (1995). The gender role strain paradigm: An update. In R. F. Levant \& W. S. Pollack (Eds.), A new psychology of men (pp. I I-32). New York: Basic Books.

PPWG GBKP. (20I4).Bahan kursus calon pertuadiaken GBKP periode 20I4-2019.Kabanjahe: Percetakan GBKP AbdiKaryaKabanjahe.

Singarimbun, E. S. (2006). Metode penelitian survai.Jakarta: LP3ES

Thompson, E. H., \& Pleck, J. H. (1986). The structure of the male norms. American Behavioral Scientist, 29, 53।-543. 